\title{
Valores e espaço público: referenciais e instrumentos para a avaliação de projetos sociais*
}

\author{
Eloisa Helena de Souza Cabral**
}

Sumário: 1. Introdução; 2. Peculiaridades da avaliação de projetos sociais; 3 . O espaço público como referencial de avaliação dos projetos sociais; 4. Fatos e valores na avaliação; 5 . O mapa de bens públicos; 6. Conclusão.

Summary: 1. Introduction; 2. Peculiarities of the evaluation of social projects; 3 . Public space as a framework for the evaluation of social projects; 4 . Facts and values in evaluation; 5 . The map of public goods; 6 . Conclusions.

Palavras-chave: avaliação; espaço público; gestão social; terceiro setor; valores.

KEY WORDS: evaluation; public space; social management; third sector; values.

As realizações das organizações sociais apresentam a natureza dual de projetarem valores sociais relevantes, associados a resultados, através dos quais pretendem impactar pessoas. Essa concepção da gestão social — como reprodutora de valores e produtora de bens públicos visando o cumprimento de uma missão — sugere que a avaliação deva considerar os vínculos entre os valores e os benefícios para inferir métricas do impacto social dos projetos. Essa vinculação e o conceito de espaço público permitem tratar as questões da intangibilidade dos benefícios, da escala local

\footnotetext{
* Artigo recebido em nov. 2010 e aceito em jun. 2011. A autora agradece à Associação Nacional de Pós-Graduação e Pesquisa em Administração (Anpad) pela oportunidade de comunicar seus resultados durante o EnAnpad 2010; à Fundação Guimarães Rosa (FGR) pelo apoio institucional; e aos dois árbitros anônimos cujas ponderações foram bem-vindas e consideradas neste texto.

** Professora titular de sociologia da Faculdade de Administração da Fundação Armando Álvares Penteado (Faap). Doutora em ciências sociais e mestre em serviço social pela Pontifícia Universidade Católica de São Paulo (PUC/SP). Professora do programa de pós-graduação da Coordenadoria Geral de Especialização, Aperfeiçoamento e Extensão (Cogeae) da PUC/SP. Membro da International Society for Third Sector Research, da Universidade Johns Hopkins, Baltimore, USA; do Núcleo de Estudos Avançados no Terceiro Setor (Neats), da PUC/SP; do Centre International de Recherche et d'Information sur l'Économie Publique, Sociale et Coopérative (Ciriec) e do Centro de Estudos Sociais (CES) da Faculdade de Economia da Universidade de Coimbra. Endereço: rua São José, 261, ap. 132 - CEP 04739-000, São Paulo, SP, Brasil. E-mail: elocabral@uol.com.br.
} 
dos projetos e da imitação dos métodos adaptados, que se mostram insuficientes para captar os valores sociais relevantes. Enfatizamos os trabalhos de H. Putnam e A. Sen para sugerir um referencial avaliativo como um conjunto de conceitos e instrumentos para o mapeamento dos bens públicos e valores desenvolvidos pelas organizações sociais. Como exemplo, apresentamos uma experiência avaliativa desenvolvida em Belo Horizonte (MG).

Values and public space: frameworks and tools for evaluation of social projects

The achievements of social organizations have a double nature as projections of values that they intend to disseminate, and as its outcomes, which should produce impact, as benefits. This conception of social management - to render values and to produce public goods for mission accomplishment - suggests that the evaluation must consider the bonds among the reproduction of values and the impact of benefits to infer evaluative metrics. This entanglement and the concept of public space allow us to face questions as the intangibility of benefits, the scale of local organizations, and the limitation of adapted methods to capture social values. We emphasize the concept of public space and the theoretical works of H. Putnam and A. Sen to suggest an evaluative framework, as an ensemble of concepts and some related instruments, as a mapping of public goods and values of social initiatives. As an example, we present an evaluative experience with a project evaluated in Belo Horizonte, MG, Brazil.

\section{Introdução}

O propósito desse artigo é oferecer um referencial de avaliação do impacto, dos valores e da economicidade dos benefícios efetivados pela gestão social de projetos e iniciativas de organizações sociais locais. Esse referencial constituise de uma abordagem conceitual normativa e dos instrumentos metodológicos decorrentes que orientam a avaliação. A abordagem considera a centralidade do conceito de espaço público e identifica os benefícios dos projetos sociais por envolverem resultados apreciáveis na forma de bens públicos produzidos e valores sociais reproduzidos pela gestão. Por sua vez, as iniciativas sociais locais caracterizam-se por vínculos peculiares de sustentabilidade econômica, apoio institucional, parcerias em atividades, ou propósitos complementares a políticas públicas, que envolvem o setor público, ou as organizações privadas, na área da responsabilidade social. A especificidade dos benefícios calcados em valores e resultados apresenta-se como um desafio aos gestores para desenvolver uma cultura própria de avaliação, nesse campo, que dialogue com as metodologias oriundas dos setores público e mercantil como técnicas cor- 
rentes e estabelecidas. Porém, esse diálogo deve garantir a identidade do método para o exame de mudanças objetivas, como fatos na qualidade de vida dos beneficiários dos projetos, e também como valores que sustentam a representação social dessa qualidade de vida considerada valiosa. A gestão social sugere argumentos de superação da dicotomia fato $\times$ valor que se apresenta como um dilema na escolha do objeto da avaliação e dificulta a aproximação do objeto de avaliação, tratando-o como intangível, ou subjetivo. Sugerimos uma abordagem normativa do espaço público de natureza intermediária, entre o Estado, o mercado e as comunidades, onde se desenvolvem as iniciativas sociais, considerando os públicos constituintes dos projetos e a relevância da vinculação entre fatos e valores sociais como conceitos fundamentais associados à peculiaridade da gestão social. O espaço público, dotado de um conjunto de atributos (visibilidade, controle, defesa social, democratização, representatividade de interesses coletivos, sustentabilidade, cultura pública, autonomia, universalidade, qualidade e efetividade), constitui-se no foco da perspectiva normativa que sugerimos seja tomada como referência para identificar os benefícios pretendidos, capazes de prover sua ampliação como ambiente de sociabilidades que permitam o florescimento do conceito de público. Enfatizamos as contribuições de Hilary Putnam e Amartya Sen, para a determinação do objeto avaliativo, dotado de valores reproduzidos em fatos que se pretende avaliar. Apresentamos os resultados obtidos na avaliação de um projeto de apoio a jovens em risco social, em Belo Horizonte (MG), como exemplo da aplicação de uma metodologia de avaliação que se vale do referencial proposto e o sintetiza em um instrumento, o mapa de bens públicos. Esse mapa, decorrente da abordagem normativa, é um inventário de valores e instrumento que permite explicitar o compartilhamento e a centralidade dos valores associados aos benefícios e resultados que se pretende avaliar. A elaboração de ferramentas apropriadas para capturar esses aspectos peculiares da gestão social mostra-se relevante para o desenvolvimento da cultura pública por meio da comunicação dos achados avaliativos que informam os atores associados a esses projetos, dando publicidade à representação valorativa dos fatos no espaço público.

\section{Peculiaridades da avaliação de projetos sociais}

A avaliação do impacto e dos resultados de projetos sociais, conduzidos por organizações sociais locais que visam ao bem-estar, é frequentemente considerada requisito das agências financiadoras, com o objetivo de monitorar 
a efetividade dos resultados alcançados ou a eficiência de sua relação custo-benefício. Esses projetos geralmente compartilham, com o setor público e com as organizações mercantis, formas de apoio econômico, representações de valores, parcerias institucionais, utilização de equipamentos comuns, vinculação de objetivos e outras interfaces no âmbito das políticas públicas e da responsabilidade social empresarial. Porém, a avaliação e suas técnicas não estão suficientemente difundidas no campo das organizações sociais. Entre as razões de natureza geral, destacam-se: a incipiente profissionalização no setor e a constatação de que as práticas de avaliação não traduzem ainda a existência de uma cultura sistemática e difundida. Entre as razões específicas, citamos: a ausência de uma metodologia específica que apreenda o conteúdo valorativo das ações sociais e a insistência em importar técnicas e argumentos tanto da área pública quanto da área privada, sem o necessário diálogo que aponte as singularidades desse novo campo.

A literatura - Anheier (2004), Cotta (1998), Cohen (1993), Contador (1997), Connel (1993 e 1995), Evers (1997), Forbes (1998), Herman (1994), Herman e Renz (1999), Jannuzzi (2006), Patton (2008), Kaplan (2001), Ramos (2009), Rossi e colaboradores (1999), Sheehan (1996), The World Bank (2002), United Way of America (1996), W.K. Kellogg Foundation (1998), Wholey e colaboradores (1994), Worthen (2004) — e as referências citadas nessas obras apresentam, entre outros, esforços de construção de metodologias, adaptações de técnicas e roteiros ou manuais de desenvolvimento de processos de avaliação que podem ser utilizados, com modificações, no campo das organizações sociais locais. Entretanto, nos exercícios avaliativos e na comunicação de seus achados, nos deparamos com o reconhecimento, nem sempre satisfatório, da natureza especial que envolve os valores reproduzidos e os resultados alcançados na gestão dessas iniciativas. Embora os procedimentos de avaliação quantitativa, de investigação qualitativa, do impacto e da economicidade estejam estabelecidos, são comuns interrogações acerca da diversidade de visões dos diferentes participantes e beneficiários das organizações; da capacidade interpretativa das abordagens, quantitativa ou qualitativa; da intangibilidade dos benefícios; das dificuldades organizacionais de implementação de sistemas de controle e da ausência de grupos de tratamento e controle fidedignos para desenhos experimentais ou quase experimentais; da limitação de métodos adaptados da área mercantil e da área pública; dos interesses dos atores a quem se destina a avaliação; e da diversidade de explicações, causais ou correlativas, sobre as consequências sociais da questão a ser abordada, dos resultados atingidos e das externalidades conseguidas. É também comum observar a recomendação de empenho para a aplicação de 
métodos lógicos de planejamento e de cuidados metodológicos que permitam apartar consistentemente as fases dos programas entre meios e fins, entre causas e efeitos, gerando uma discussão extemporânea para a escala local dos projetos das organizações que atuam em arranjos institucionais de parcerias. Aponta-se, também, a insuficiência do exame formal dos indicadores e de sua mensuração para a interpretação do impacto das ações, consideradas por vezes intangíveis.

As adaptações de técnicas de monitoramento da área privada (NEF, 2008; Ibase, 2009) valorizam a perspectiva econômica ou mesmo contábil, oferecendo instrumentos importantes em relação ao aspecto da sustentabilidade financeira, que apreendem nessa ótica os esforços das mudanças sociais contidos nesses programas. As adaptações das técnicas oriundas da área pública sugerem, por outro lado, indicadores sociais mais gerais, às vezes insensíveis às escalas locais dos projetos. Em ambos os casos, o que se verifica é a captação de um aspecto pelo exercício avaliativo, comprometendo, por um lado, a capacidade de informação da avaliação de comunicar seus achados a públicos tão diversos como aqueles acessados nos projetos sociais e, de outro, desencadeando uma reação adversa e de desconfiança dos gestores.

Apesar dos esforços na área, o desenvolvimento da cultura de avaliação entre as organizações sociais pode ser considerado incipiente (Cabral, 2006). Os problemas identificados nessa cultura deficiente de avaliação não estão ligados às técnicas de coleta e tratamento de dados e às análises estatísticas necessárias, que podem ser superados pelo esforço técnico, mas residem em dois momentos específicos do processo avaliativo. Em primeiro lugar, no desenho, na concepção desse processo, que se ressente da falta de um referencial específico que indique o objeto da avaliação e desenvolva a partir dele os indicadores associados. Em segundo lugar, na interpretação dos resultados e modelos estatísticos, e na consequente comunicação dos achados da avaliação aos gestores, que não ocorre de modo completo, ensejando interpretações e leituras particulares, baseadas nos aspectos relacionados aos recursos econômicos envolvidos, e determinísticas das causas sociais abordadas, as quais nem sempre são acessadas pelos projetos. Este artigo pretende contribuir com o primeiro desses tópicos, com a apresentação de um instrumento, o mapa de bens públicos, e do exemplo de sua aplicação às fases iniciais da avaliação de um projeto social. Esse avanço permite sugerir argumentos para o esclarecimento das questões relativas ao segundo tópico.

O caso das organizações sociais que desenvolvem projetos sociais locais sugere que outra abordagem da avaliação pode ser proposta e experimentalmente verificada. Podem-se examinar as indagações acima, reconhecendo que 
apontam, na ótica da gestão social, para os valores pretendidos e a efetividade dos resultados, e indicam a necessidade metodológica de que a avaliação enfatize quatro conceitos peculiares da natureza social dessa gestão. Trata-se, em primeiro lugar, do conceito de "missão" relativa à reflexão pública dos indivíduos acerca das assimetrias da questão social; da constatação dos "vínculos" entre os valores e resultados, ambos objeto de mensuração; da relevância do conceito de "públicos constituintes" com necessidades, capacidades e interesses diversos, que projetam esses valores e pretendem esses resultados; e da natureza especial do "espaço público" onde essas iniciativas se desenvolvem. Com o concurso desses conceitos, é possível construir um referencial de avaliação, ou o instrumento conceitual de análise que identifica os valores do objeto que se pretende avaliar, como espaço modelo da avaliação, o evaluative space de Sen (1997), quando o autor refere-se à necessidade de construir um instrumento que esclareça e explicite quais os valores, e os objetos dotados de valor, que se pretende avaliar. O referencial que apresentamos neste artigo faz parte de metodologia específica para a avaliação de projetos desenvolvidos no espaço público por organizações sociais em suas escalas locais e procura atentar para as especificidades da gestão social fundada na reprodução de valores e produção de bens públicos nesse espaço público.

\section{O espaço público como referencial de avaliação dos projetos sociais}

Considera-se a organização social como uma iniciativa privada e local, instituída por indivíduos que interpretam a questão social, declaram uma missão, e determinam objetivos de mudar as condições estruturais associadas ao desenvolvimento e à proteção social relativos a essa questão, assumindo valores a serem reproduzidos e resultados a serem alcançados em sua atuação. A escala da localidade reflete o fato de as organizações sociais, objeto desta reflexão, desenvolverem, elas próprias, seus projetos e estarem associadas a intervenções, formais ou informais, em determinada localidade para a qual são formulados projetos específicos nas mais diversas áreas. A diversidade de áreas de atuação reflete a primeira identificação da missão institucional com o conceito de público, oriundo, nesse sentido, da publicidade da questão social (Wanderley, 2000) em termos das assimetrias estruturais da vida social (Cabral, 2004).

Para expressar os aspectos sociais de suas missões, as organizações sociais desenvolvem um tipo peculiar de gestão, que vincula a produção de be- 
nefícios sociais tangíveis - como fatos que impactarão indivíduos à reprodução de valores sociais - como representações sociais de estados pretendidos (Cabral, 2006a). Nesse contexto, os valores são crenças que motivam construções privadas e coletivas, indicando metas, permitindo escolhas, dirigidas a padrões e orientadas por critérios. Os estados pretendidos organizam-se por escolhas sociais que os indivíduos identificam a partir desses valores, para acessar padrões de vida, que, no caso dos projetos sociais em tela, concernem ao desenvolvimento e à proteção sociais. Essa vinculação de fatos e valores é reproduzida socialmente, comunicando e explicando a racionalidade da missão organizacional. Em sua relação local, o imbricamento de fatos e valores manifesta-se no compartilhamento de resultados pretendidos pelas instâncias das comunidades, do mercado e do Estado com valores sociais buscados pelos participantes dos projetos dessas instâncias. Essa é uma das bases sobre as quais se dá a negociação, a decisão e a gestão dos projetos que vinculam organizações sociais com o desenvolvimento local. Assim se articulam os esforços conjuntos, as parcerias, econômicas ou institucionais, como formas de movimentação e compartilhamento desses entes.

As organizações sociais acessam diversas fontes de recursos sociais (fundos públicos, trabalho voluntário, doações privadas de pessoas e empresas, entre outras) enquanto articulam diferentes grupos sociais que se expressam como seus públicos constituintes (beneficiários, doadores, voluntários, empregados e instituidores) e que se identificam por diferentes valores, determinando expectativas, necessidades, capacidades, interesses e representações sociais da missão (Designaremos, sumariamente, por Encir este conjunto de expectativas, necessidades, capacidades, interesses e representações sociais.). Esses recursos diversos e as frações dos públicos que se associam ao empreendimento social é que indicam a capilaridade por meio da qual a missão da organização representa o conjunto das Encir.

Assim, a avaliação de projetos sociais envolve especificidades decorrentes de valores e de públicos diversos, detentores e compartilhadores desses valores, e deve ser desenvolvida para elucidar os valores transmitidos e os benefícios alcançados na forma de bens públicos e não apenas como medida de resultados atingidos, os quais, embora sejam metas factuais, possuem representações diversas para os públicos articulados nas ações, de acordo com suas Encir. São, em última instância, os valores que, de modo coordenado e convergente, são compartilhados pelos públicos, permitindo a unificação desses resultados no processo de gestão, pois na perspectiva deles é que os resultados são considerados valiosos e representativos. Desse modo, reconhecer a centralidade da reprodução dos valores, com o objetivo de estimar sua repre- 
sentação na produção dos bens públicos pretendidos como benefícios sociais, e sua percepção diversificada pelos públicos constituintes, indica pistas para superar a alegada intangibilidade desses benefícios que, muitas vezes, é usada como argumento para justificar a ausência da avaliação. É nessa evidência que se apoia o mapa de bens públicos que sugerimos adiante.

Outra constatação relevante para a avaliação refere-se ao espaço em que se dá a produção desses bens públicos e a reprodução dos valores sociais. De acordo com Cabral (2007), consideramos esse campo de relações sociais em que atividades, ações, empreendimentos e organizações sociais privadas, envolvidas por propósitos solidários, expressam suas missões e participam da produção de bens públicos de proteção e desenvolvimento sociais como um espaço relacional em que lógicas diversas, discursos e racionalidades emergindo do Estado, do setor mercantil e da comunidade, são interconectados por um propósito comum de proteção e desenvolvimento sociais. É a área intermediária de realização de esforços privados projetados sobre a questão social, e as organizações sociais surgem como formas privadas e circunscritas de atuação para realizar suas missões.

Esse espaço tem recebido denominações diversas, que envolvem características das organizações que nele atuam, como terceiro setor, sociedade civil organizada, organizações não lucrativas, setor não governamental, entre outras. Essas nomenclaturas, que podem assumir um sentido exclusivamente classificatório, fazem com que esse espaço seja frequentemente tratado apenas como um conjunto de organizações similares (não lucrativas, não governamentais, voluntárias, de investimento social privado, responsabilidade social e inúmeras outras), desprezando-se sua natureza abstrata, como intermediária no que concerne às racionalidades do Estado, do mercado e da comunidade e, ao mesmo tempo, marcada pela concretude da intervenção social, seja ela formal ou informal. Tratando-as assim, como conjunto, o que nos parece limitado, substitui-se a concepção sociológica de sua natureza inter-relacional e normativa por uma simplificação classificatória que inibe a expressão dos valores como construções sociais e transfere a representação desses valores para suas decorrências em termos de meras características organizacionais, sujeitas a adequações circunstanciais. Essa concepção classificatória faz com que a avaliação de projetos contemple indicadores que apuram tão somente essas características instrumentais, as quais, embora importantes, prescindem de um esforço avaliativo acerca dos valores que as identifiquem, induzindo à adoção de métricas que se limitam a mensurar a utilidade dos bens na perspectiva de sua instrumentalidade. Sujeita-se, desse modo, a avaliação a importar métodos, técnicas e concepções testados nas áreas privada e pública, 
e a recair nos enganos que apontamos anteriormente, afastando-se da gestão e empobrecendo o conteúdo avaliativo de informações relevantes e de sua comunicação entre os públicos.

Cabral (2005 e 2007) ressalta a natureza inter-relacional desse espaço social, apoiando-se em Evers (1995) para se referir ao espaço público intermediário e híbrido em que se articulam as ações sociais da espécie que nos interessa. Nessas oportunidades, a autora designou o espaço de modo amplo pelo acrônimo TS, do termo internacionalmente aceito de terceiro setor (Cattani, 2009), identificando, nele, o local social em que se realizam novas sociabilidades apoiadas no conceito de público e intermediárias entre o Estado, o mercado e a comunidade. É assim, por exemplo, que Defourny (2009) examina a pertinência da economia social ao campo das iniciativas do TS. Para o tratamento metodológico da avaliação, é preferível referirmo-nos diretamente ao termo espaço público, coerentemente com sua natureza, reforçando a concepção sociológica normativa que valoriza o conceito de sua publicidade. Nesse sentido, superamos a discussão acerca das áreas de atuação e das características organizacionais, assumindo como foco da identificação os quatro conceitos apontados.

Essa concepção normativa do local social onde se realizam essas sociabilidades apresenta-o como um espaço público equipado de atributos, que Cabral (2007) identificou nos valores: representação de interesses coletivos, democratização, qualidade, efetividade, visibilidade, cultura pública, universalidade, autonomia, controle, defesa social e sustentabilidade. Alguns desses atributos foram examinados por Wanderley (1988 e 2006) em seu estudo das instituições educacionais comunitárias, propondo-os como pilares do conceito de "público não estatal". Essa estrutura de valores, inerente ao espaço público, impõe que as escolhas dos indivíduos, e os indicadores que apurarão essas escolhas, reflitam as hierarquias de valores que as representações dos públicos constituintes elaboram a partir das relações interpessoais por meio das quais fruem os bens públicos, compartilham valores e constroem o florescimento do conceito de público. A consideração desse espaço público induz, nesse sentido, à construção de um referencial normativo para a concepção e leitura do conteúdo informativo da avaliação na perspectiva dos significados valorativos que motivaram os indivíduos a se associarem nos propósitos, e dialoga com a gestão social baseada nesses significados. O mapa de bens públicos que oferecemos na sequência é um esforço para materializar esse procedimento, e sua aplicabilidade à construção de indicadores é um exemplo de sua capacidade de explicitação desse conteúdo.

A consideração do espaço público no processo avaliativo permite compreender que as missões comunicam uma interpretação da questão social atra- 
vés de valores que se pretende sejam reproduzidos e resultados que sejam alcançados, para a garantia de determinada qualidade de vida em sociedade, recuperando o papel das sociabilidades, educativas e civilizatórias, engendradas nas organizações, como local social de expressão interpessoal de conflitos dos interesses dos públicos diversos na produção daqueles bens e sua capacidade de produzi-los. A consideração desse espaço dota a investigação avaliativa de um fundamento crítico (Horkheimer, 1975) no sentido de apreender, do ponto de vista teórico, a ocorrência nesse campo do desenvolvimento de um processo de ampliação do conceito de público, como valor permanente na confluência e na comunicação que articula os públicos constituintes e as organizações.

Esse conceito de espaço público está relacionado à possibilidade de realizar as expressões privadas manifestadas nas interpretações coletivas sobre a questão social que emanam da apropriação desigual do desenvolvimento e da proteção social. Esse espaço pode ser identificado por sua estrutura de atributos normativos de modo a dialogar com a concepção apresentada inicialmente da gestão social como produtora de bens e reprodutora de valores, atuando no campo de fluxos e influências, tensões e interesses presentes na sociedade, que se explicitam, para essas organizações sociais, em modos cooperativos e solidários das relações interpessoais. Nesse sentido, a presença dos atributos garante a publicização das iniciativas e de sua pertinência ao espaço público de realização de valores e resultados, no qual a avaliação dos projetos pretende captar o impacto dos benefícios na forma desses valores e resultados mensuráveis que garantem a realização da missão.

\section{Fatos e valores na avaliação}

Para a teoria da avaliação, persiste uma disputa entre os aspectos qualitativos e quantitativos (House, 2001) que, embora possa ser resolvida tecnicamente a partir de análises estatísticas consolidadas, remete-nos, em seus aspectos interpretativos, comunicativos e conceituais, à conhecida dicotomia fato $\times$ valor, investigada teoricamente por Hilary Putnam (2002) no campo da filosofia. Como exemplo de sua argumentação, Putnam aponta a importância de superar essa dicotomia para o exame das ideias de Amartya Sen acerca da possibilidade de comparação interpessoal dos padrões de qualidade de vida (Sen, 1997; Walsh, 2003). A dicotomia fato $\times$ valor forçava a apresentação dos fatos como observáveis, enquanto os valores eram tratados como manifestações 
individuais, ou trans-substancializações coletivas, relativas a situações subjetivas e a julgamentos incomensuráveis entre si, que induziam os indivíduos a manifestarem classificações e preferências. Putnam e Walsh mostraram que, apesar da distinção metodológica entre fatos e valores, não se pode abordar a realidade com um critério que "fatora" os achados em uma "parte descritiva", tomados como valores, e uma "parte avaliativa", tomada como fato. Isso porque as ações dos homens em sociedade desenvolvem sociabilidades a partir de condições, escolhas e propósitos, parâmetros nos quais os fatos são valorizados como fatos à medida que expressam os valores determinados socialmente (Putnam, 2005). É nesse sentido que o espaço público está equipado de um conjunto de valores que permite atribuir aos fatos nele desenvolvidos a qualidade peculiar de serem públicos.

Para a avaliação dos projetos desenvolvidos localmente pelas organizações, um referencial deve ser capaz de expressar, para os impactos avaliados, sua vinculação essencial com os valores socialmente pretendidos pelos públicos constituintes que os fruem, na figura dos bens e na representação dos valores. Essa fruição consiste na realização dos bens e valores pelos públicos e indica, para a avaliação, a necessidade de estender aos impactos a consideração dos valores que estes mesmos impactos representam para os públicos considerados que os capacitam a fruí-los. Nesse sentido, o referencial que sugerimos decorre da concepção do evaluative space proposto por Amartya Sen (1999), Alkire (2002), Robeyns (2006) e Comim (2008) em suas abordagens das capabilities, de modo a permitir a especificação dos valores e dos bens que devem ser tomados como objetos dotados de valor para serem avaliados. O problema prático encetado por essa constatação é a explicitação dos valores compartilhados pelos públicos partícipes dos projetos e acessados pela gestão social da organização.

Essa concepção normativa da gestão social, decorrente da concepção de espaço público, pressupõe a possibilidade de escolhas sociais pelos públicos constituintes e, nesse sentido, dialoga com as contribuições de Sen e seus colaboradores, tratando a especificidade da avaliação dos projetos sociais localizados a partir dos valores substantivos que induzem a definição dos objetos avaliáveis. Se os indivíduos realizam escolhas sociais, a tarefa da avaliação é apanhar estas escolhas em contextos próprios e específicos, considerando-as associadas aos benefícios pretendidos. Nesse sentido, avaliar um projeto é o processo através do qual atribuímos medida aos estados alcançados e reconhecidos, valorativamente, entre os objetivos do projeto atingidos pela fruição, de que os públicos constituintes são capazes, dos bens públicos produzidos 
e tornados acessíveis, na perspectiva de suas Encir. O problema prático da avaliação é determinar as métricas que representem, nessa perspectiva, esses estados em que valores e bens estão justapostos em sua valorização e fruição, contribuindo para comunicar as informações e esclarecer as escolhas, que esses públicos realizam.

No caso da avaliação de projetos sociais locais, devem ser considerados os conceitos apresentados para dar conta das peculiaridades da gestão nessa área. Por exemplo, tomando o conceito de públicos constituintes, essas escolhas são motivadas por Encir convergentes e complementares de atores que se articulam para atuar na situação-problema e determinam diferentes modos de fruição dos bens. Considerando os conceitos de bem público e de gestão social, os objetivos do projeto e os estados que serão mensurados devem contemplar o exame desses bens públicos e desses valores.

Tomemos, por exemplo, um projeto que, entre seus objetivos, pretenda garantir o uso do tempo livre de jovens, de modo a afastá-los do risco social. Podemos mensurar o objetivo uso do tempo pela variação de um indicador em duas situações: entre indivíduos participantes do projeto e entre um grupo semelhante a estes, mas não integrante do projeto. Porém, os projetos sociais são assim definidos, pois envolvem os públicos constituintes em ações de esclarecimento, cujo objetivo é garantir que o uso do tempo seja valorizado socialmente, para que a atitude dos indivíduos que vivem em uma determinada sociedade seja alterada, mudando estruturalmente determinado estado de coisas. O problema avaliativo é que o uso do tempo obedece a valores socialmente confluentes como esposados por indivíduos socialmente vinculados, mas possivelmente contraditórios, como explicitações das Encir desses atores que o avaliam e escolhem. As mudanças suscitadas no uso do tempo são resultado da realização de um fato (alteração positiva das formas de uso do tempo) e da comunicação de valores (valor do tempo livre e disciplina para o uso do tempo e liberdade de escolha), de modo a capacitar a fruição de um bem (alternativas de uso do tempo de acordo com as Encir dos públicos constituintes). Essa é a materialidade das tensões da gestão social desse projeto, vincular esses fatos e esses valores, como benefícios do projeto para a sociedade. Portanto, essa vinculação deve ser investigada e aproveitada pela avaliação para definir o estado em que se encontra o problema "uso do tempo" e, nesse sentido, podemos dizer que, identificando os valores, podemos identificar os fatos dotados desses valores que pretendemos mudar com o projeto. Esse conjunto de fatos e valores compõe o espaço avaliativo e define os objetos da avaliação. 


\section{0 mapa de bens públicos}

Como exemplo da aplicação dessa abordagem centrada em valores e referenciada no conceito de espaço público, apresentamos os resultados parciais da metodologia de avaliação que considera, em sua fase inicial, a construção de um instrumento, o "mapa de bens públicos" (MBP) de um projeto de apoio a jovens em situação de risco, desenvolvido pela Fundação Guimarães Rosa (FGR) de Belo Horizonte (MG). Tomando a situação de risco desses jovens como um problema social, a FGR acessa recursos sociais diversos e pretende disseminar valores de respeito, uso do tempo, disciplina, entre outros, realizando ações educativas e esportivas após o horário escolar, utilizando-se de instalações públicas compartilhadas com a Polícia Militar. A organização tem por hipótese que seus valores institucionais garantem afastamento do risco social e ocupação do tempo ocioso com atividades educacionais e esportivas. Sua principal fonte de apoio é a Polícia Militar, cujos equipamentos e instalações, em um quartel urbano, são usados para integrar os jovens em risco com agentes públicos interessados nessa aproximação. O projeto ocorre há cinco anos, atende a aproximadamente 200 indivíduos e conta com apoio e doações de empresas e pessoas físicas, além de contribuições dos instituidores e da Polícia Militar.

A avaliação envolveu também os aspectos econômicos e de impacto social do projeto. Para tanto, ele foi examinado de acordo com o referencial do espaço público; foi construído o MBP, tratado neste artigo; elaborados questionários, indicadores, índices compostos; levantados os custos sociais; calculado o impacto; e desenvolvido um sistema de informações e tratamento estatístico. Esses achados avaliativos, relativos aos aspectos da economicidade e do impacto do projeto, excedem o objetivo deste artigo e serão objeto de apresentação futura.

O MBP, parte estratégica e orientadora da metodologia, é um inventário dos bens e valores desenvolvidos na gestão social, articulados de acordo com sua relação normativa, de modo a captar os objetivos que os públicos constituintes pretendem atingir e as necessidades às quais o projeto atende, na perspectiva das Encir dos públicos. Portanto, os valores subordinam os objetivos na elaboração do MBP.

O MBP pode ser abordado, também, como um instrumento para verificar o cumprimento da missão e, nesse sentido, perfaz uma etapa do processo avaliativo, para vincular valores e resultados como benefícios mensurados por indicadores desse cumprimento. Tomado no contexto da avaliação, o MBP é construído a partir do referencial do espaço público e corrobora para afastar 
a pretensa intangibilidade dos benefícios, outrora tomados como expressões abstratas ou como resultados desconectados dos valores sociais que os conformam. Os atributos do espaço público expressos pelos valores: representatividade de interesses coletivos, democratização, qualidade, efetividade dos resultados, visibilidade social, cultura pública, universalidade, autonomia, controle, defesa social e sustentabilidade compõem a perspectiva que orienta a apropriação ao MBP, de acordo com a tabela 1, dos benefícios pretendidos e bens públicos promovidos. Os resultados esperados, cujas métricas conformam os indicadores da avaliação, sugerem a mensuração que permite indicar o florescimento do conceito de público por meio do cumprimento da missão.

Para a elaboração, o MBP pode ser tratado como um desenho do projeto, no qual se ressaltam as conexões entre os conceitos de recursos, atividades, produtos, resultados e benefícios, de modo a garantir a articulação entre eles e cumprir os objetivos pretendidos na concepção do problema. A justificativa dessa metodologia decorre do conceito de modelo lógico (Ferreira e Cassiolato, 2007). Como uma metodologia utilizada desde os anos 1960, possui várias interpretações e modificações, principalmente como ferramenta de planejamento. A designação de lógico decorre de que, em sua concepção, esses conceitos referem-se a uma situação-problema que o projeto aborda, e quando explicitados na análise do projeto estão encadeados por relações de finalidade e causalidade.

Porém, o MBP diferencia-se do modelo lógico e se identifica como instrumento original de avaliação por suspender esses juízos causais e de finalidade e introduzir a explicitação exclusiva dos valores, como juízo normativo que se esforça para apontar os vínculos entre a missão e as ações decorrentes. As relações de causalidade e finalidade são secundárias, pois não se está preocupado com sua possível justificativa operacional, ou de planejamento, mas sim em explicitar os valores e os resultados pressupostos pelos públicos na construção das racionalidades de sua ação social e na identificação do objeto avaliativo.

Há, entretanto, uma razão teórica fundamental para a superação dos vínculos causais e de consequência imediatos. O problema é que ao assumirmos que um resultado e as condições necessárias à sua obtenção estão relacionados por uma ligação de causa e efeito, ou de meios e fins, estamos assumindo como imediata uma relação que considera que a disponibilidade de meios iguais resulta na obtenção de fins iguais, desprezando a mediação dos "fatores de conversão" como nos ensina Robeyns (2006) em seu exame da abordagem das capabilities. Essa mesma questão está na raiz da elucidativa crítica de Sen à teoria da justiça de Rawls, mostrando que a igualdade de recursos, ou de 
meios, não é garantia de realização das possibilidades dos indivíduos (Nussbaun e Sen, 1995).

A insistência nas conexões causais ou consequenciais esquematiza e empobrece as interdependências que os indivíduos enfrentam em suas vidas em sociedade. Elas podem ser úteis para o planejamento de atividades, porém, no caso de a avaliação forçar o estabelecimento de conexões, anteriormente à pesquisa, pode sugerir correlações estatísticas não comprovadas posteriormente. Ao reduzir um projeto a um esquema de pareamento de meios e fins, tomam-se de modo imediato e unilateral as possibilidades de escolha da vida em sociedade e, portanto, do mesmo modo imediato e unilateral, as oportunidades reais que os indivíduos realizam a partir de condições similares. Para efeito da avaliação, a referência consequencial, comum nas abordagens de políticas públicas e nas avaliações exclusivamente econômicas, solicita que os indicadores apontem aferições nem sempre acessadas e dificulta a comunicação dos achados avaliativos, pois impõe objetivos para os quais não há garantia de realização a partir das causas oferecidas, nem uma identificação com os conteúdos da missão, para a escala local dos projetos que nos interessam. Consideramos que insistir na relação causal, ou consequencial, é uma imprecisão que dificulta o aproveitamento da avaliação e o desenvolvimento de uma cultura na área, mesmo porque os projetos e as atividades avaliadas não decorrem necessariamente de motivações causais, mas sim de interpretações pelos públicos constituintes de aspectos da questão social, os quais pouco acesso têm às causas efetivas dos problemas que enfrentam. A avaliação deve assim guardar relação íntima com a missão compartilhada e seus valores e não com possíveis justificativas causais nem sempre ao alcance dos objetivos dos projetos.

Apenas a consideração dos valores e dos conteúdos das hierarquias desses valores para a construção do MBP permite superar a dificuldade no desenho de uma avaliação, estabelecendo pesos e métricas próprias para aquilatar as representações normativas com que os indivíduos consideram suas realizações interpessoais em sua ação organizada. De fato, é introduzido um determinado componente individualista nessa abordagem, porém a gestão social dos projetos das organizações locais também possui um componente de consideração das individualidades, ao se dedicar a mudar estados objetivos de realização de indivíduos que desenvolvem sociabilidades.

Apresentamos, na tabela 1, um resumo do MBP para o projeto Portas Abertas. Observemos as colunas do MBP em uma primeira leitura: a coluna "recursos" permite identificar os custos sociais do projeto, que atingem os públicos constituintes acessados pela FGR; a coluna "atividades" identifica os 
temas sociais aos quais a organização se dedica e que devem ser coerentes com a missão institucional e com os objetivos do projeto; a coluna "bens públicos" é a mais importante, pois identifica os fatos e valores produzidos pela gestão social. A expressão desses bens comunica aos públicos constituintes, realmente, o que o projeto efetiva. A explicitação dos bens atribui ao projeto um novo patamar de realização e relevância social; a coluna "resultados e mudanças" permite reconhecer os indicadores que serão utilizados na avaliação, facilitando sua comunicação aos públicos e conectando-se com a missão, a qual sempre pretende mudar, transformar, melhorar um estado e, nesse sentido, sua realização deve ser mensurada; e, finalmente, a coluna "benefício" permite descobrir, no benefício gerado, o impacto que será mensurado pela variação dos indicadores.

Tabela 1

O mapa de bens públicos - fatos e valores

\begin{tabular}{|c|c|c|c|c|}
\hline $\begin{array}{l}\text { Recursos } \\
\text { (necessidades) }\end{array}$ & Atividades & $\begin{array}{l}\text { Bens públicos } \\
\text { (produtos) }\end{array}$ & $\begin{array}{l}\text { Resultados } \\
\text { (mudanças) }\end{array}$ & Benefício \\
\hline $\begin{array}{l}\text { Orçamentos, } \\
\text { instalações da } \\
\text { PM, refeições, } \\
\text { material didático, } \\
\text { voluntários, } \\
\text { custos indiretos, } \\
\text { infraestrutura, } \\
\text { custos de } \\
\text { oportunidade, } \\
\text { doações, apoios. }\end{array}$ & $\begin{array}{l}\text { Educação } \\
\text { Proteção }\end{array}$ & $\begin{array}{l}\text { Brinquedoteca, } \\
\text { oficinas, treinamento } \\
\text { dos recursos } \\
\text { humanos, disciplina, } \\
\text { respeito, confiança, } \\
\text { reconhecimento, } \\
\text { uso de tempo, } \\
\text { identidade pessoal, } \\
\text { autoestima, apoio } \\
\text { da família, coesão } \\
\text { social, acesso a } \\
\text { oportunidades. }\end{array}$ & $\begin{array}{l}\text { Desempenho escolar, } \\
\text { frequência escolar, } \\
\text { desenvolvimento } \\
\text { cognitivo, relação } \\
\text { idade/série, percepção } \\
\text { de valores, percepção } \\
\text { da qualidade do } \\
\text { projeto, } \\
\text { valorização da família, } \\
\text { uso de drogas, uso } \\
\text { de fumo, eventos } \\
\text { de conflito com a } \\
\text { lei, uso do tempo, } \\
\text { gravidez adolescente, } \\
\text { sentimento de } \\
\text { segurança, valores. }\end{array}$ & $\begin{array}{l}\text { Aproximação com } \\
\text { o poder legítimo, } \\
\text { comportamento } \\
\text { responsável, } \\
\text { oportunidades de } \\
\text { desenvolvimento. }\end{array}$ \\
\hline Custos sociais & Temas sociais & Fatos e valores & Indicadores & Impacto \\
\hline
\end{tabular}

É importante ressalvar que a conexão lógica entre as colunas do MBP prescinde da correlação causal ou consequencial por entender que estas são correspondentes às vidas dos indivíduos e podem ser acessadas por outras análises sociológicas competentes e específicas. Para a elaboração desse instrumento normativo, o MBP, submetemos a uma perspectiva valorativa o arranjo 
social dos bens disponibilizados pelo projeto e, nesse sentido, solicitando que se retenha o valor como fonte do desenvolvimento do projeto, porque assim é, conforme apontamos no início, que as organizações realizam sua missão na confluência dos públicos na gestão social. $\mathrm{O}$ fato é que os projetos dessas organizações não têm a extensão e a escala que nos permitam solicitar deles o acolhimento das relações causais, que podem e devem ser atingidas em outras instâncias da vida social e pela pesquisa com essa finalidade. É importante repetir que não estamos refutando nexos causais ou consequenciais, mas apenas solicitando que, para a elaboração do MBP, nos detenhamos, metodologicamente, nos valores que organizam os projetos e a gestão social. É nesse mesmo sentido que Cabral (2009) aponta que a gestão social mimetiza a relação fato $\times$ valor e deve assim ser acompanhada pelos processos avaliativos.

A consideração desse vínculo valorativo entre as colunas do MBP permite que o impacto pretendido exceda a significação de um resultado que atinge um determinado grupo de indivíduos e passa a representar a investigação de um estado de possibilidades ao qual os públicos constituintes, em sua totalidade, mostram-se mais ou menos capazes de ascender.

Essas observações, quando aplicadas à leitura mais detalhada do MBP, sugerem o método de preenchimento das colunas. Do ponto de vista operacional, é necessário que sua elaboração conte com o concurso de um grupo de responsáveis pelas diversas áreas e gestores do projeto, que denominaremos grupo de participantes da avaliação, em um ambiente dinâmico e dialogado, no qual se pretende construir o conjunto ordenado de respostas. O preenchimento das colunas acompanha a seguinte ordem: benefício, bens públicos, resultados, recursos, e, por fim, atividades. Perguntamo-nos, primeiramente, pelos benefícios pretendidos, como valores fundamentais assumidos pelos instituidores em sua concepção da questão social abordada. A resposta preenche a coluna "benefícios". Substituindo a inflexão causal ou consequencial por uma relação valorativa, perguntamos, na sequência, quais bens, como fatos dotados de valores, compõem o acervo das materializações da gestão social em sua prática interpretativa da efetivação do projeto na direção dos benefícios. Dessa maneira, preenchemos a coluna "bens públicos", como produtos objetivos que serão fruídos pelos públicos. O mesmo questionamento aplica-se ao preenchimento da coluna "resultados", na qual estão inscritos os resultados da fruição dos bens pelos públicos e a esperada transmissão dos valores. A pergunta, nesse ponto, é acerca dos valores que os bens da coluna anterior modificam. Assim construímos a coluna "resultados", na qual se lê a métrica apropriada pelos indicadores, que aparecem naturalmente como as mudanças efetivadas, encontradas na resposta. Para o 
preenchimento da coluna "recursos", é habitual valermo-nos de juízo causal, sugestivo da necessidade dos meios para a implementação dos bens. Porém, esses meios só terão efetividade se adstritos aos valores que os tornam viáveis naquela situação. Assim é que recorremos aos valores que apropriam, para os públicos, os ingressos que compõem os bens públicos. O objetivo é descobrir a totalidade dos recursos que, nessa perspectiva, assumem a função de necessidades valorizadas pelos públicos.

A elaboração do mapa é uma experiência esclarecedora para explicitar os vínculos que tornam presentes nos projetos as mais diversas fontes de contribuição, de apoio, de trabalho, de sociabilidades que se formam e que valorizam socialmente a iniciativa. Essa percepção é fundamental para a apropriação, inclusive econômica, da multiplicidade de bens disponibilizados socialmente, cuja identificação só é possível a partir do levantamento da relevância social que os valores permitem expressar e que se reproduz em termos de trabalho, capital social, voluntariado, solidariedade e principalmente em termos de disponibilidade e uso do tempo pelos participantes. De outra forma, esses recursos permaneceriam obscuros ou com sua identificação, ou quantificação, comprometida entre o acervo das necessidades sociais do projeto.

Na tabela 2 apresentamos o conjunto das Encir apontadas pelos públicos constituintes manifestando as diferentes percepções que os identificam. Operacionalmente, seu preenchimento resulta de pesquisa qualitativa, por meio de entrevistas com elementos representativos dos diversos públicos e com o concurso da percepção dos responsáveis e gestores participantes. Apenas o compartilhamento de valores, pelo esforço da gestão social do projeto, permite adequar as percepções de modo congruente aos objetivos e esta é a constatação que solicita o afrouxamento das relações causais e consequências. Aqui novamente nos valemos dos atributos do espaço público (representatividade de interesses coletivos, democratização, qualidade, efetividade dos resultados, visibilidade social, cultura pública, universalidade, autonomia, controle e defesa social, e sustentabilidade) como referencial. Esses atributos desempenham um papel central, como os valores que orientam a pertinência ao conceito de público, determinando os quesitos da investigação. Assim, por exemplo, a percepção da qualidade do projeto deve ser um quesito investigado, pois corresponde a um atributo requisitado das ações sociais no espaço público. Essa ligação, que se constitui em um exemplo da vinculação fato $\times$ valor, garante que a qualidade pretendida será referenciada na representação do participante e comunicará a ele, na medida de seu incremento, um ingrediente de positividade da iniciativa e sua valorização. 
Tabela 2

Mapa de bens públicos - Encir dos públicos constituintes

\begin{tabular}{|c|c|c|c|c|c|}
\hline & Expectativas & Necessidades & Capacidades & Interesses & Representações \\
\hline Instituidores & $\begin{array}{l}\text { Resolver o } \\
\text { problema social }\end{array}$ & $\begin{array}{l}\text { Atingir } \\
\text { resultados }\end{array}$ & Gestão social & $\begin{array}{l}\text { Compartilhar } \\
\text { valores }\end{array}$ & $\begin{array}{l}\text { Cumprimento da } \\
\text { missão }\end{array}$ \\
\hline Família & $\begin{array}{l}\text { Encaminhar o } \\
\text { jovem }\end{array}$ & Apoio & Acolhimento & Assistência & Proteção \\
\hline Comunidade & Diminuir risco & Coesão & Apoio & Desenvolvimento & Coesão \\
\hline Funcionários & $\begin{array}{l}\text { Valorizar seu } \\
\text { trabalho }\end{array}$ & Remuneração & $\begin{array}{l}\text { Dedicação } \\
\text { pessoal }\end{array}$ & $\begin{array}{l}\text { Realização } \\
\text { pessoal }\end{array}$ & $\begin{array}{l}\text { Sentido do } \\
\text { trabalho }\end{array}$ \\
\hline Voluntários & Contribuir & Participar & Tempo & $\begin{array}{l}\text { Realização } \\
\text { pessoal }\end{array}$ & Participação \\
\hline Polícia Militar & $\begin{array}{l}\text { Melhorar a } \\
\text { prevenção }\end{array}$ & $\begin{array}{l}\text { Realizar } \\
\text { trabalho social }\end{array}$ & Exemplo & Imagem & Integração \\
\hline Público-alvo & Proteção & Assistência & $\begin{array}{l}\text { Alegria, } \\
\text { disposição }\end{array}$ & Uso do tempo & Participação \\
\hline
\end{tabular}

Entre os benefícios coletados no MBP, ressaltamos a "aproximação com o poder legítimo", escolhido pelos participantes para dar conta do desenvolvimento das sociabilidades a que nos referimos e do atingimento de um estado que permite a interlocução dos públicos e o compartilhamento dos valores. As Encir dos instituidores, construídas a partir da missão institucional e calcadas em valores de civismo, organização, respeito e regras sociais, espelham a lógica dos instituidores para abordar a questão social e indicar o benefício pretendido.

Excede os objetivos deste artigo examinar outros achados da avaliação, como a construção de indicadores, a elaboração de instrumentos de coleta, o tratamento estatístico e a comunicação de dados, a construção de índices sociais compostos, a análise da economicidade do projeto, seu impacto social e possibilidade de sua monetarização.

Para os objetivos deste artigo, é suficiente assegurar que o MBP se mostrou relevante ao apoiar a escolha das variáveis significativas na análise fatorial e de componentes principais do conjunto de 27 indicadores; para a construção de índices compostos que mensuram o impacto social, a intersetorialidade, a taxa de doação e outras medidas que dependem de modelos estatísticos; na apropriação de todos os recursos sociais disponíveis e validados para o exame da economicidade do projeto; e como elemento aglutinador na participação dos públicos no processo avaliativo e na comunicação de seus resultados. 
O conjunto de indicadores do público-alvo e de suas famílias (frequência escolar, rendimento escolar, valores da educação, valores institucionais, imagem das instituições, confiança na família, capacidade de sustentabilidade da família, ocupação do tempo, uso negativo do tempo, uso positivo do tempo, capacidade de comprometimento de renda, valores de acesso, participação, valores de cultura pública, qualidade do entorno social, uso de drogas lícitas, uso do corpo, percepção da segurança do jovem, percepção da segurança da família, gravidez adolescente, violência na família, estabilidade da família, conflito com a ordem) engloba indicadores associados a fatos (por exemplo, a frequência escolar) e indicadores associados a valores, tomados como motivadores de atitudes. Outros indicadores foram construídos para o exame das Encir dos outros públicos constituintes (por exemplo, o indicador de capacidade contributiva; a responsabilização com o projeto; a hierarquização de valores de funcionários, instituidores e doadores; e de satisfação e participação nos resultados). Os dados submetidos à análise de componentes principais resultaram em um índice composto por sete dimensões (valores do jovem, valores da família, educação, controle e defesa social, estabilidade familiar, sustentação econômica, imagem institucional). Os significados expressos na tabela 2 foram usados como foco para dotar de relevância a composição dos indicadores em um índice agregado de cumprimento da missão pelo projeto.

Mas, principalmente, a explicitação dos valores e bens públicos em quadros mostrou-se um instrumento esclarecedor das perspectivas e unificador das linguagens pelas quais os públicos abordavam e comunicavam suas sociabilidades. Assim, ao identificar variáveis e recursos, na perspectiva dos valores que os dotam de significados acessados pelos vários públicos constituintes, estamos listando e hierarquizando preferências que afetam esses públicos e que nem sempre estão explícitas nos projetos.

O MBP foi construído como um instrumento que contribuísse para o investigador responder a questões propostas por Sen (1995) acerca de quais são os objetos de valor. E quão valiosos são esses objetos. Para o projeto Portas Abertas, os objetos de valor são os bens públicos produzidos e a avaliação terá por objetivo estabelecer o impacto de sua fruição, como um benefício. Esse impacto é definido pela métrica naturalmente obtida com os indicadores de mudança a partir daquela fruição. Considerando o conjunto de bens públicos, ou os objetos de valor, no caso do valor público referendado pelos atributos do referencial do espaço público, o MBP constrói, nesse sentido, o evaluative space sugerido por Sen. Assim, fundado no referencial do espaço público, o MBP nos permite superar o mero indicativo de impacto, como resultado da avaliação, que poderia, sem essas considerações, ser submetido sempre à su- 
gestiva questão: impacto do quê? Essa questão sempre decorre das tentativas de contornar uma alegada intangibilidade dos benefícios das iniciativas sociais semelhantes ao projeto Portas Abertas. As abordagens oriundas das políticas públicas e as avaliações de custo-benefício e custo-efetividade que prescindem do exame normativo dos projetos apropriam o impacto a partir de indicadores estruturais nem sempre suscetíveis às hierarquias dos valores no espaço público. Dessa forma, embora métodos estatísticos de regressão possam garantir a confiabilidade do impacto, subsiste uma determinada artificialidade, principalmente relatada por gestores (Cabral, 2007) na identificação das mudanças sociais por esses indicadores.

O referencial sustentado pelos valores assegura que os bens públicos estão talhados como promotores de benefícios que garantem a reprodução dos valores e estão conectados, pela gestão social, ao conjunto de possibilidades de efetivação de mudanças mensuráveis na sua fruição pelos indivíduos. O impacto, referido a essa concepção normativa do espaço público, pode então ser associado à missão e tomado como uma medida da realização social das possibilidades proporcionadas pela disseminação e pelo compartilhamento dos valores.

Construído, o MBP, como instrumento que expressa essas relações, não há por que aventar a razão da intangibilidade dos benefícios como um entrave à avaliação, pois as relações entre os bens, os valores e o impacto estabelecem a correspondência entre o objeto da avaliação dotado dos valores e os valores especificados e acordados pelos participantes.

Tomemos como exemplo ilustrativo da utilidade do MBP para construção de indicadores o caso do indicador de "uso do tempo". Após sua identificação como valor no MBP, construiu-se um conjunto de questões para apurar esse uso, valorizado de acordo com as Encir dos públicos. Seria elementar mensurar a utilidade do tempo pela quantificação do uso, porém, o conceito solicita o exame da valorização das alternativas e da presença efetiva das alternativas como oportunidades reais às quais os indivíduos são capazes de ascender.

Essa observação orientou o esforço com o público-alvo do projeto para construir a hierarquia das escolhas e posteriormente propor, no questionário de avaliação, as questões que contemplassem três indicadores: o primeiro, "ocupação do tempo" referente às escolhas entre listas de atividades nas quais se arranjam opções consideradas positivas e negativas; o segundo, que solicita a valoração individual, em escalas de Likert, de cada uma das alternativas consideradas negativas; e o terceiro, que solicita a valoração individual de cada uma das alternativas consideradas positivas. Esses indicadores 
representam o esforço avaliativo para apurar as dimensões quantitativas e qualitativas das oportunidades contidas nas escolhas valorizadas pelos indivíduos submetidos ao projeto. A tabela 3 apresenta os grupos de opções, positivas e negativas, apuradas pela pesquisa preliminar e entrevistas com os participantes.

Os indivíduos são instados a assinalar, em cada grupo, as atividades que realizam regularmente por mais de duas vezes por semana. Apura-se o resultado da subtração: número de escolhas do grupo A menos o número de escolhas do grupo B. Ele indica o número líquido de escolhas valiosas para o objetivo de afastamento do ócio. O indicador de "ocupação do tempo" é tomado como esse resultado convenientemente normalizado. Quanto maior o número de escolhas, mais opções, mais alternativas valiosas o indivíduo tem e, de acordo com a hipótese, utiliza quantitativamente melhor seu tempo.

Para avaliar qualitativamente o valor individual dessas escolhas, os indivíduos são solicitados a atribuir notas, de acordo com sua concordância, a cada uma das afirmações acerca das opções de uso do tempo, de acordo com o exemplo exposto na tabela 4.

Tabela 3

Grupos de opções, positivas e negativas, apuradas pela pesquisa

\begin{tabular}{|ll|}
\hline Grupo A (uso positivo) & Grupo B (uso negativo) \\
\hline Ler & Assistir à TV \\
Estudar & Encontrar amigos \\
Fazer limpeza da casa & Dormir durante o dia \\
Ajudar um familiar & Ficar deitado no sofá \\
Cuidar de irmãos & Namorar \\
Consertar coisas & Ir à festa \\
Fazer compras & Jogar baralho \\
Praticar esporte & Jogar videogame \\
Ir à Igreja & Ingerir bebida alcoólica \\
Trabalhar & Ir à lan house \\
Visitar parentes & Ficar na vila \\
\hline
\end{tabular}

Tabela 4

Notas atribuídas a cada uma das opções de uso do tempo

Indicador de uso positivo do tempo

Atribuir nota de 0 a 6 para cada atitude do grupo A. Atribuir nota de 0 a 6 para cada atitude do grupo B.

Ex.: Eu ajudo na limpeza da minha casa. [__ _ Ex.: Eu costumo ficar deitado no sofá quando chego

da escola, ou durante o meu tempo livre. 
A média e a normalização das notas atribuídas oferecem os indicadores de "uso positivo" e "uso negativo" do tempo. São medidas como essas que permitem construir índices agregados e vincular fatos, em termos de quantidade de escolhas e valores, em termos de percepção das opções feitas para atitudes associadas aos valores identificados no MBP.

Além de explicitar o conteúdo do projeto em termos de valores e fatos mensuráveis, o processo de elaboração do MBP desempenha outras funções relevantes na avaliação. Internamente, possibilita a compreensão, pelo público, da organização acerca dos objetivos de suas tarefas no projeto, sejam elas administrativas, técnicas, burocráticas, decisórias ou de apoio, dotando de significado as análises financeiras e estatísticas usuais do processo de avaliação econômica e de impacto. Com relação à totalidade dos públicos constituintes, o MBP permite a comunicação dos resultados do processo de avaliação, incorporando elementos valorativos por meio dos quais esses públicos reconhecem suas identidades na forma dos valores apreendidos.

\section{Conclusão}

A partir da identificação das peculiaridades da gestão social dos projetos de desenvolvimento das organizações sociais, é possível estabelecer a relevância da investigação dos valores sociais associados aos resultados esperados dessas intervenções. Desse modo decorre a necessidade de superação de um dilema que contrapõe indevidamente os fatos e os valores nos processos de avaliação. O trabalho do avaliador para esclarecer essa vinculação e apurar o impacto do projeto pode ser apoiado pelo MBP, construído em consonância com um referencial de atributos do espaço público no qual as atividades acontecem.

Os valores reproduzidos no espaço público são tomados como fundamentais para a construção do referencial que norteia o processo avaliativo. $\mathrm{O}$ MBP apoia a avaliação por considerar o compartilhamento de valores como um vínculo que permite a identificação dos bens, dos benefícios e das métricas coerentes com as Encir dos públicos constituintes. Em seu aspecto técnico, a explicitação dos valores transmitidos e os benefícios gerados permitem que o processo de avaliação seja um agente de comunicação eficiente dos resultados, que passam a se revestir de significado objetivo para aqueles públicos.

Nesse sentido, o MBP pretende contribuir como um instrumento para desenvolver uma cultura de avaliação e a cultura pública nas organizações, pois exige, para sua elaboração, a participação efetiva dos envolvidos no projeto avaliado. No aspecto da meta-avaliação, o MBP, com o compartilhamento de valores na definição de bens, objetivos e métricas, pode se revelar uma con- 
tribuição à materialização da perspectiva interpessoal e dialógica, solicitada por Putnam (1994), para o exame crítico das atividades sociais cooperativas. Quando o investigador defronta-se com o momento de reflexão solitária para a coordenação das diretrizes e foco das avaliações de questões onde estão em exame sociabilidades e construções que orientam vidas de pessoas, os valores sociais compartilhados pelos públicos dessas iniciativas sugerem orientações seguras dessas escolhas.

\section{Referências}

ALKIRE, Sabina. Valuing freedons: sens's capability approach and poverty reduction. New York: Oxford University Press, 2002.

ANHEIER, Helmut K. Civil society: measurement, evaluation, policy. London/Sterling: Earthscan, 2004.

CABRAL, Eloisa Helena de Souza. Espaço público e controle para a gestão social no terceiro setor. Serviço Social e Sociedade, n. 86, p. 30-55, 2006.

CABRAL, Eloisa Helena de Souza. Gestão social no terceiro setor: avaliação de processos e missão institucional. Oficina do Ces, Faculdade de Economia da Universidade de Coimbra, 2003.

CABRAL, Eloisa Helena de Souza. O lugar social do terceiro setor e as dualidades de sua gestão. In: FONTES, Breno; MARTINS, Paulo Henrique. Redes, práticas associativas e gestão pública. Recife: UFPE, 2006a. p. 209-218.

CABRAL, Eloisa Helena de Souza. Reptos para o terceiro setor: pertinência ao espaço público não estatal na perspectiva da gestão social. Tese (doutorado) — Pontifícia Universidade Católica de São Paulo, São Paulo, 2004.

CABRAL, Eloisa Helena de Souza. Terceiro setor: gestão e controle social. São Paulo: Saraiva, 2007.

CABRAL, Eloisa Helena de Souza. Une double perspective du controle sur la gestion sociale. In: Concepts of the Third Sector: the european debate ISTR-Crida. Paris, 2005. Disponível em: <www.crida-fr.org > . Acesso em: 20 jun. 2009.

CABRAL, Eloisa Helena de Souza; MUZY, P.T. Improving public culture through the evaluation of outcomes and values in social enterprises. In: EMES Conferences Selected Papers Series II EMES INTERNATIONAL CONFERENCE ON SOCIAL ENTERPRISES, EURICSE, Trento ECSP-T09-25. 2009. Disponível em: <www.emes. net/index.php?id=499>. Acesso em: 20 abr. 2010. 
CATTANI, A.D. et al. Dicionário internacional da outra economia. Coimbra: Almedina, 2009.

COHEN, Ernesto; FRANCO, Rolando. Avaliação de projetos sociais. Petrópolis: Vozes, 1993.

COMIM, Flávio; QIZILBASH, Mozaffar; ALKIRE, Sabina. The capability approach: concepts, measures and applications. New York: Cambridge University Press, 2008.

CONNEL, James et al. (Ed.). New approaches to evaluating community initiatives: concepts, methods and contexts. Washington: The Aspen Institute, 1993.

CONNEL, James et al. (Ed.). New approaches to evaluating community initiatives ii: theory, measurement and analysis. Washington: The Aspen Institute, 1995.

CONTADOR, Claudio R. Projetos sociais: avaliação e prática. São Paulo: Atlas, 1997.

COTTA, Tereza C. Metodologia de avaliação de programas e projetos sociais: análise de resultados e de impacto. Revista do Serviço Público, Brasília, n. 49, p. 103-124, 1998.

DEFOURNY, Jacques. Closing plenary to the II EMES International Conference. Trento, 2009. Disponível em: <www.emes.net>. Acesso em: 12 set. 2009.

EVERS, Adalbert. Part of the welfare mix: the third sector as an intermediate area. Voluntas, New York, v. 6, n. 2, p. 159-182, 1995.

EVERS, Adalbert. Quality development - part of a changing culture of care in personal social services. In: EVERS, Adalbert et al. (Ed.). Developing quality in personal social services. Aldershot, UK: Ashgate, 1997.

FERREIRA, Helder; CASSIOLATO, Marthe; GONZALES, Roberto. Como elaborar modelo lógico de um programa: roteiro básico. Brasília: Instituto de Pesquisa Econômica Aplicada (Ipea), 2007.

FERREIRA, Sílvia Maria Dias. O papel das organizações do terceiro sector na reforma das políticas públicas de protecção social. Dissertação (mestrado) — Faculdade de Economia, Universidade de Coimbra, Coimbra, 2002.

FORBES, Daniel Measuring the unmeasurable: empirical studies of nonprofit organization effectiveness from 1977 to 1997. Nonprofit and Voluntary Sector Quarterly, v. 27, n. 2, 1998.

HABERMAS, Jürgen. The structural transformation of the public sphere: an inquiry into a category of bourgeois society. Cambridge: Polity, 1989. 
HERMAN, Robert D. The jossey-bass handbook of nonprofit leadership and management. San Francisco: Jossey Bass Publishers, 1994.

HERMAN, Robert D.; RENZ, David O. Theses on nonprofit organizational effectiveness. Nonprofit and Voluntary Sector Quarterly, v. 28, n. 2, p. 107-126, 1999.

HORKHEIMER, Max. Filosofia e teoria crítica. In: HORKHEIMER, Max et al. Os pensadores. São Paulo: Abril, 1975. v. XLVIII, p. 163-170.

HOUSE, Ernest Unfinished business: causes and values. American Journal of Evaluation, v. 22, n. 3, p. 309-315, 2001.

IBASE. Instituto Brasileiro de Análises Sociais e Econômicas. Disponível em: <www. balancosocial.org.br>. Acesso em: 12 set. 2009.

JANNUZZI, Paulo M.; PATARRA, Neide Lopes. Manual para capacitação em indicadores sociais nas políticas públicas e em direitos humanos. Rio de Janeiro: Ence, 2006.

KAPLAN, Robert S. Strategic performance and management in nonprofit organizations. Nonprofit Management and Leadership, v. 11, n. 3, 2001.

NEF. New Economic Foundation. SROI: valuing what matters. Londres: NEF, 2008. Disponível em: <www.neweconomics.org > . Acesso em: 12 ago. 2009.

NUSSBAUM, Martha; SEN, Amartya. The quality of life. Oxford: Clarendon Press, 1995.

PATTON, Michael. Utilization-focused evaluation. San Francisco: Sage, 2008.

PORTUGAL, Silvia. As redes informais de apoio à maternidade. Revista Crítica de Ciências Sociais, Coimbra, n. 42, p. 155-178, 1995.

PUTNAM, Hilary. Comunicação privada. 2005.

PUTNAM, Hilary. For ethics and economics without the dichotomies, Review of Political Economy, v. 15, n. 3, 2003.

PUTNAM, Hilary. The collapse of the fact/value dichotomy. Cambridge: Harvard University Press, 2002.

PUTNAM, Hilary. Words and life. Cambridge: Harvard University Press, 1994.

RAMOS, Marília. Aspectos conceituais e metodológicos da avaliação de políticas e programas sociais. Planejamento e Políticas Públicas, n. 32, p. 95-114, 2009.

ROBEYNS, Ingrid. The capabilities approach in practice. Journal of Political Philosophy, v. 14, n. 3, p. 351-376, 2006.

ROSSI, Peter H. et al. (Ed.). Evaluation: a systematic approach. Thousand Oaks: Sage Publications, 1999. 
SEN, Amartya. Capability and well-being. In: NUSSBAUM, Martha; SEN, Amartya. The quality of life. Oxford: Clarendon Press, 1995. p. 30-54.

SEN, Amartya. Quality of life and economic evaluation. Academia Sinica Economic Papers, v. 25, n. 3, 1997.

SEN, Amartya. Quality of life and economic evaluation. Academia Sinica Economic Papers, v. 25, n. 3, 1997.

SEN, Amartya. The economics of life and death. Scientific American, v. 268, n. 5, p. 40-47, 1993.

SEN, Amartya. The possibility of social choice. Nobel Lecture. The American Economic Review, v. 89, n. 3, p. 349-378, 1999.

SHEEHAN, R. Mission accomplishment as philanthropic organization effectiveness. Nonprofit and Voluntary Sector Quarterly, n. 25, p. 110-123, 1996.

THE WORLD BANK. Monitoring and evaluation: some tools, methods and approaches. Washington: The World Bank, 2002.

UNITED WAY OF AMERICA. Measuring program outcomes: training kit. United Way of America, Alexandria, 1996.

W.K. KELLOGG FOUNDATION. Evaluation handbook. W.K. Kellogg Foundation, 1998.

WALSH, Vivian. Sen after Putnam. Review of Political Economy, v. 15, n. 3, p. 315394, 2003.

WANDERLEY, Luiz Eduardo. Enigmas do social. In: CASTEL, Robert; WANDERLEY, Luiz E.; BELFIORE-WANDERLEY, Mariangela. Desigualdade e questão social. São Paulo: Educ, 2000. p. 163-234.

WANDERLEY, Luiz Eduardo. O ensino público não estatal: uma inovação? Ciência e Cultura, v. 40, n. 4, p. 365-370, 1988.

WANDERLEY, Luiz Eduardo. Uma proposta inovadora: o público não estatal. Serviço Social e Sociedade, São Paulo, n. 86, p. 78-89, 2006.

WHOLEY, Joseph S. et al. Handbook of practical program evaluation. San Francisco: Jossey-Bass, 1994.

WORTHEN, Blaine et al. Avaliação de programas: concepções e práticas. São Paulo: Gente, 2004. 
